\title{
ANALISIS KETIDAKRATAAN JALAN MENGGUNAKAN APLIKASI SMARTPHONE DI KOTA PALANGKA RAYA
}

\section{ANALYSIS OF ROAD ROUGHNESS USING SMARTPHONE APPLICATION IN PALANGKA RAYA CITY}

\author{
Devia \\ Jurusan Teknik Sipil Universitas Palangka Raya \\ Korespondensi: deviadev90@ gmail.com
}

\begin{abstract}
ABSTRAK
Survei ketidakrataan IRI (International Roughness Index) adalah survei profil memanjang untuk mendapatkan nilai ketidakrataan jalan. Pelaksanaan survei ini bertujuan untuk memberikan gambaran umum terhadap kondisi jalan dan memberikan masukkan dalam optimasi pemeliharaan dan rehabilitasi jaringan jalan yang ada dikota Palangka Raya. Data yang digunakan untuk keperluan analisis adalah data IRI berdasarkan survei pada beberapa jalan yang mewakili kondisi di Kota Palangka Raya dengan bantuan aplikasi RoadLabPro menggunakan kendaraan roda empat. Hasil penelitian menunjukan bahwa ruas jalan Beruk Angis rata-rata nilai IRI sebesar $9 \mathrm{~m} / \mathrm{km}$. Pada ruas jalan Yos Sudarso dengan nilai rata-rata IRI sebesar 5,06 m/km. Pada ruas jalan Tjilik Riwut nilai rata-rata IRI sebesar $4,53 \mathrm{~m} / \mathrm{km}$. Pada ruas jalan Beruk Angis mengalami ketidakrataan jalan dengan kondisi kerusakan ringan hingga kerusakan berat. Penanganan yang tepat untuk ruas jalan Beruk Angis adalah perlu dipertimbangkan untuk peningkatan jalan. Pada ruas jalan Yos Sudarso dan Tjilik Riwut mengalami ketidakrataan dengan kondisi sedang dan penanganannya dengan pemeliharaan secara berkala.
\end{abstract}

\section{Kata Kunci: IRI, Ketidakrataan Jalan, Kondisi Jalan}

\begin{abstract}
The International Roughness Index (IRI)'s survey is a longitudinal profile survey to determine Roughness Index of road. The purpose of this survey is to provide an overview of road conditions and provide input in optimizing the maintenance and rehabilitation of the existing roads in the city of Palangka Raya. The data used for analysis is IRI's data from surveys on several roads that represent conditions in Palangka Raya City with the RoadLabPro application on car. The results showed that the Beruk Angis road had an average IRI value of $9 \mathrm{~m} / \mathrm{km}$. On the Yos Sudarso road with an average IRI value of $5.06 \mathrm{~m} / \mathrm{km}$. On the Tjilik Riwut road section, the average IRI value is $4.53 \mathrm{~m} / \mathrm{km}$. On the Beruk Angis road section with conditions of light damage to severe damage. Proper handling of the Beruk Angis road section needs to be considered for road improvement. The Yos Sudarso and Tjilik Riwut roads with moderate conditions and are handled with regular maintenance.
\end{abstract}

Keywords: IRI, Road Roughness, Road Condition 


\section{PENDAHULUAN}

Struktur perkerasan jalan akan mengalami proses kerusakan secara progresif sejak jalan dibuka untuk lalu lintas. Untuk mengatasi hal ini diperlukan suatu metode untuk menentukan kondisi jalan agar dapat disusun dalam program pemeliharaan jalan yang diperlukan.

Pada penelitian ini diambil data secara visual dari penelitian terdahulu serta data survei menggunakan aplikasi RoadLabPro untuk membandingkan data secara visual dan menggunakan aplikasi RoadLabPro. Dalam penelitian ini meliputi jalan Tjilik Riwut, Jalan Yos Sudarso dan Jalan Beruk Angis Kota Palangka Raya. Dari ketiga jalan tersebut mewakili klasifikasi jalan menurut fungsinya serta mengalami kerusakan jalan berdasarkan jenisnya dari yang ringan hingga berat.

\section{TINJAUAN PUSTAKA Kerusakan Jalan}

Kerusakan jalan dapat dibedakan menjadi kerusakan Struktural dan Kerusakan Fungsional. Kerusakan Struktural adalah kerusakan dari satu atau lebih komponen perkerasan yang mengakibatkan perkerasan tidak dapat lagi menanggung beban lalu lintas.

Kerusakan Fungsional adalah suatu kondisi kerusakan dimana kenyamanan dan keamanan dari pengguna jalan terganggu dan biaya operasi kendaraan (BOK) meningkat.

Kerusakan struktural dan kerusakan fungsional dapat diperbaiki dengan membangun ulang perkerasan dan dengan cara pemeliharaan

\section{Jenis Kondisi Jalan}

Jenis kondisi jalan sangat mempengaruhi dalam tingkat pemeliharaan jalan. Jenis kondisi jalan dapat diklasifikasikan sebagai berikut (Dirjen Bina Marga, 1995):

\section{Jalan dengan kondisi Baik}

Jalan dengan kondisi baik adalah jalan dengan permukaan perkerasan yang benar rata, tidak ada gelombang dan tidak ada kerusakan permukaan

2. Jalan dengan kondisi sedang

Jalan dengan kondisi sedang adalah jalan dengan kerataan permukaan perkerasan sedang, mulai ada gelombang tetapi tidak ada kerusakan permukaan

3. Jalan dengan kondisi rusak ringan
Jalan dengan kondisi rusak ringan adalah jalan dengan permukaan perkerasan sudah mulai bergelombang, mulai ada kerusakan permukaan dan penambalan (kurang dari 20\% dari luas jalan yang ditinjau).

4. Jalan dengan kondisi rusak

Jalan dengan kondisi rusak berat adalah jalan dengan permukaan perkerasan sudah banyak kerusakan seperti bergelombang, retak-retak buaya dan terkelupas yang cukup besar (20-60\% dari luas jalan yang ditinjau) disertai dengan kerusakan lapis pondasi dengan kerusakan lapis pondasi seperti amblas, sungkur dan sebagainya.

\section{Klasifikasi Kerusakan Jalan}

Klasifikasi kerusakan jalan menurut Bina Marga adalah:

\section{a. Kerusakan Struktural}

Jenis kerusakan struktural menurut Bina Marga adalah Retak (Cracking), Perubahan Bentuk (Deformation), Cacat Permukaan (Surface Disintegration), Pengausan (Polished Aggregate), Kegemukan (Bleeding), Penurunan pada Bekas Penanaman Utilitas (Utility Cut Depression).

b. Kerusakan Fungsional

Kerusakan fungsional pada jalan adalah kegiatan pemeliharaan jalan menurut Bina Marga. Kegiatan koreksi diterapkan pada perkerasan beraspal yang sudah mengalami kerusakan dengan derajat berat tetapi dengan penyebaran setempat, antara lain: lubang, amblas, gelombang, retak buaya.

Tujuan kegiatan proteksi adalah mempertahankan nilai kekuatan, tingkat keamanan, tingkat kenyamanan, kekedapan permukaan. Diselenggarakan secara berkala mencakup daerah permukaan yang luas dan tambahan nilai kekuatan yang diperhitungkan rendah.

\section{Ketidakrataan Permukaan (Roughness)}

Ketidakrataan permukaan adalah kondisi permukaan yang berhubungan dengan sifat fungsional dan struktural perkerasan aspal.

Pengujian ketidakrataan bertujuan untuk mengetahui tingkat ketidakrataan permukaan, pada satuan panjang jalan tertentu. Nilai ketidakrataan permukaan dinyatakan dengan nilai IRI (International Roughness Index), yaitu panjang 
kumulatif turun naik permukaan per satuan panjang. Dalam hal ini satuan IRI biasanya dinyatakan dalam meter turun naik per kilometer panjang jalan $(\mathrm{m} / \mathrm{km})$.

\section{Aplikasi RoadLab Pro}

Aplikasi RoadLab Pro dirancang sebagai alat pengumpulan data untuk insinyur oleh The World Bank dalam kolaborasi dengan Beldor Center Softteco and Progress Analytics LLC. Aplikasi ini mengevaluasi ketidakrataan jalan dengan IRI, kondisi jalan, jaringan jalan peta. Untuk menggunakan aplikasi, perangkat mobile harus ditempatkan pada permukaan yang stabil di dalam kendaraan Anda, sebaiknya dipasang vertikal dan erat pada kaca depan kendaraan.

\section{International Roughness Index (IRI)}

International roughness index (IRI) adalah parameter ketidakrataan yang dihitung dari jumlah kumulatif naik turunnya permukaan arah profil memanjang dibagi dengan jarak/panjang permukaan yang diukur. Sedangkan menurut (Dirjen Binamarga, 2010) IRI adalah indeks internasional yang menunjukkan besaran ketidakrataan permukaan jalan dalam satuan $\mathrm{m} / \mathrm{km}$. parameter Parameter IRI digunakan dalam menentukan kondisi konstruksi jalan, yang dibagi atas empat kelompok. Penilaian kondisi jalan beraspal berdasarkan nilai IRI dijelaskan oleh Tabel 1.

Tabel 1. Penilaian Kondisi Jalan Beraspal Berdasarkan Nilai IRI

\begin{tabular}{|c|c|c|}
\hline $\begin{array}{c}\text { Kondisi } \\
\text { Jalan }\end{array}$ & IRI $(\mathrm{m} / \mathrm{km})$ & Kebutuhan Penanganan \\
\hline Baik & IRI $<4$ & Pemeliharaan rutin \\
\hline Sedang & $4<\mathrm{IRI}<8$ & Pemeliharaan Berkala \\
\hline $\begin{array}{l}\text { Rusak } \\
\text { Ringan }\end{array}$ & $8<\mathrm{IRI}<12$ & Peningkatan Jalan \\
\hline $\begin{array}{c}\text { Rusak } \\
\text { Berat }\end{array}$ & IRI $>12$ & $\begin{array}{l}\text { Peningkatan Jalan/ } \\
\text { Rekonstruksi }\end{array}$ \\
\hline
\end{tabular}

Sumber : Dirjen Bina marga, 2005.

\section{METODE}

Penelitian ini bertujuan untuk menganalisis ketidakrataan pada beberapa jalan yang ada di Kota Palangka Raya. Survei lapangan dengan pengukuran IRI dengan menggunakan aplikasi RoadLab Pro yang dipasang di dashboard mobil. Pengamatan dilakukan dengan interval per $100 \mathrm{~m}$ dan diambil sebanyak tiga kali dengan kecepatan $20 \mathrm{~km} / \mathrm{jam}$ pada jalan kategori rusak dan 40 $\mathrm{km} / \mathrm{jam}$ pada jalan kategori sedang. Waktu survei dihindari pada jam puncak untuk menghindari pengereman mendadak. Pengujian menggunakan kendaraan roda empat.

Data Sekunder diambil dari penelitian terdahulu pada jalan tersebut dengan mengetahui tingkat kerataan jalan sebelumnya. Data Primer diambil dari hasil pengukuran IRI dari aplikasi RoadLab Pro.

Peralatan yang digunakan adalah kendaraan roda empat, smartphone dengan aplikasi RoadLab Pro, alat tulis, formulir survei dan kamera.

Teknik analisis data dengan perhitungan kondisi fungsional jalan dengan metode IRI yang diperoleh dievaluasi dengan menggunakan standar Pedoman Bina Marga.

\section{HASIL DAN PEMBAHASAN}

Dari hasil analisis IRI menggunakan aplikasi RoadLab Pro maka secara rinci nilai IRI pada tabel dan Gambar dibawah ini:

\section{Jalan Beruk Angis}

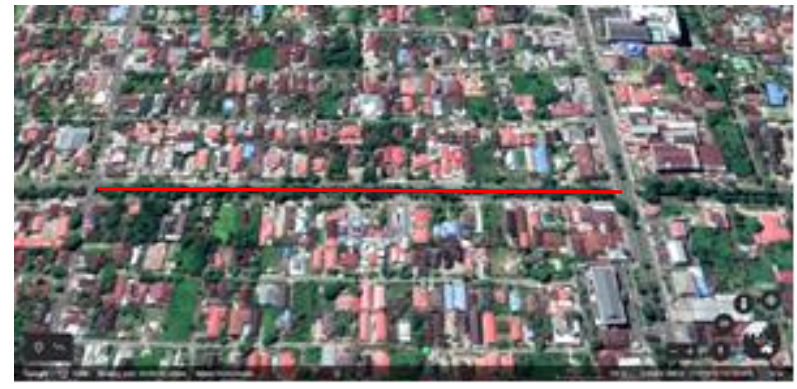

Gambar 1. Lokasi Jl. Beruk Angis Sumber: Google earth, 2021

Kondisi jalan Beruk Angis di Kota Palangka Raya seperti pada gambar dibawah ini yaitu: 


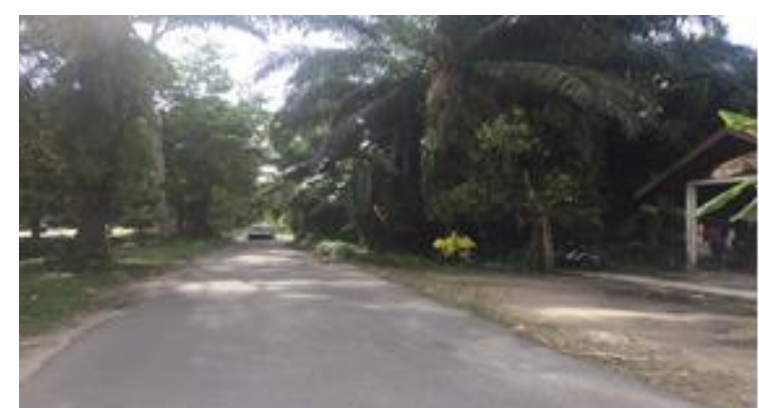

Gambar 2. Segmen I Jl. Beruk Angis

Sumber: Hasil survei 2021

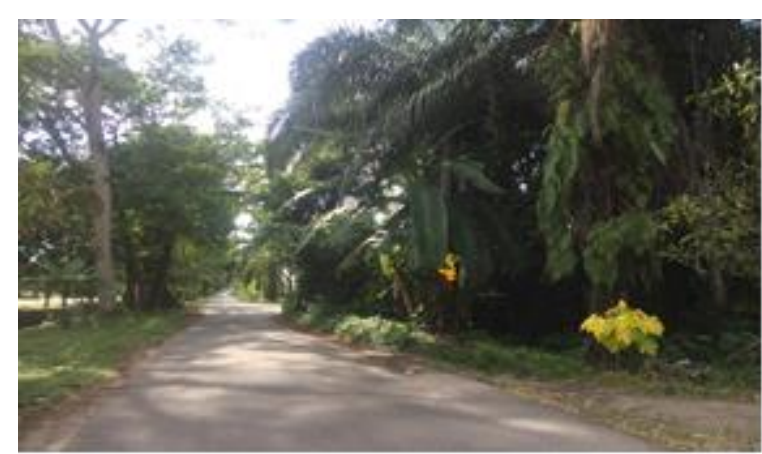

Gambar 3. Segmen II Jl. Beruk Angis Sumber: Hasil survei 2021

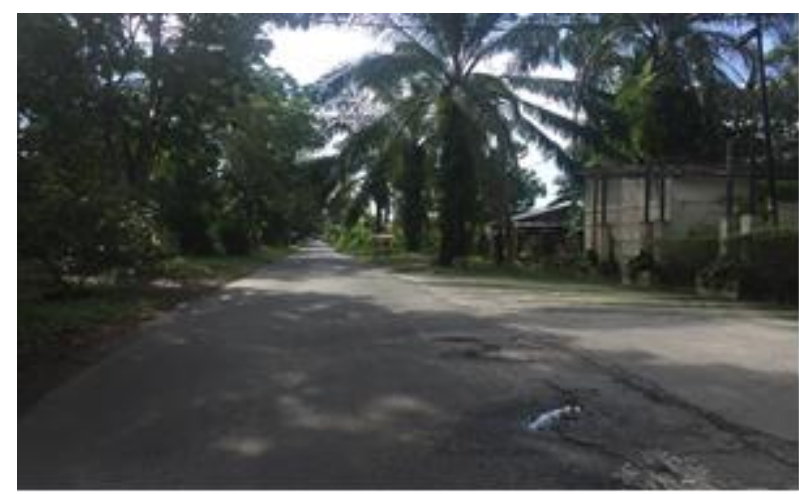

Gambar 4. Segmen III Jl. Beruk Angis Sumber: Hasil survei 2021

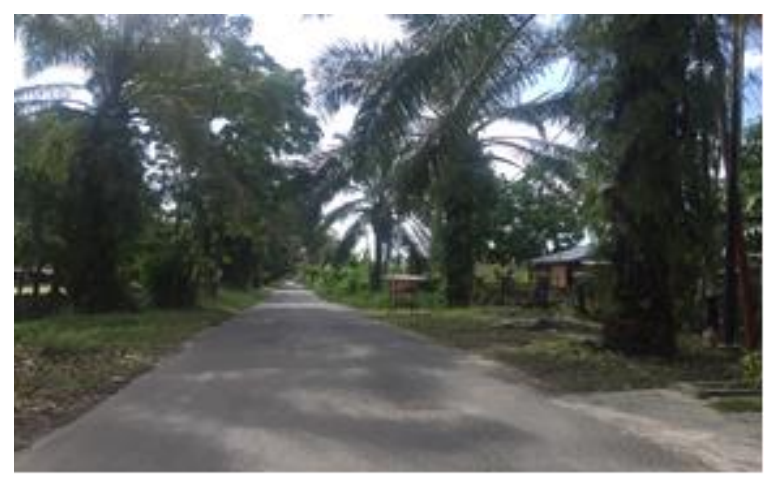

Gambar 5. Segmen IV Jl. Beruk Angis Sumber: Hasil survei 2021

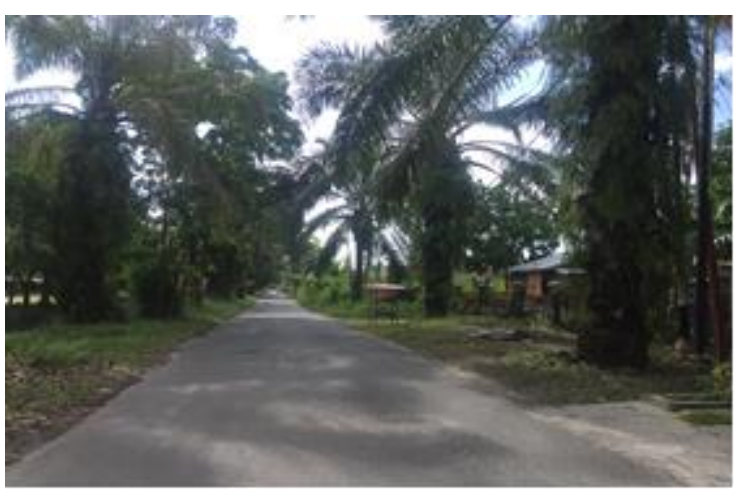

Gambar 6. Segmen V Jl. Beruk Angis Sumber: Hasil survei 2021

Hasil nilai IRI pada jalan Beruk Angis secara rinci terdapat pada tabel $\mathbf{2}$ dan Gambar $\mathbf{2}$ dibawah ini:

Tabel 2. Nilai IRI jalan Beruk Angis

\begin{tabular}{ccc}
\hline Segmen & Panjang $(\mathbf{m})$ & $\begin{array}{c}\text { Nilai IRI } \\
(\mathbf{m} / \mathbf{k m})\end{array}$ \\
\hline I & 100 & 12,59 \\
II & 100 & 7,62 \\
III & 100 & 9,13 \\
IV & 100 & 5,85 \\
V & 100 & 9,8 \\
\hline
\end{tabular}

Sumber : Hasil Analisis, 2021

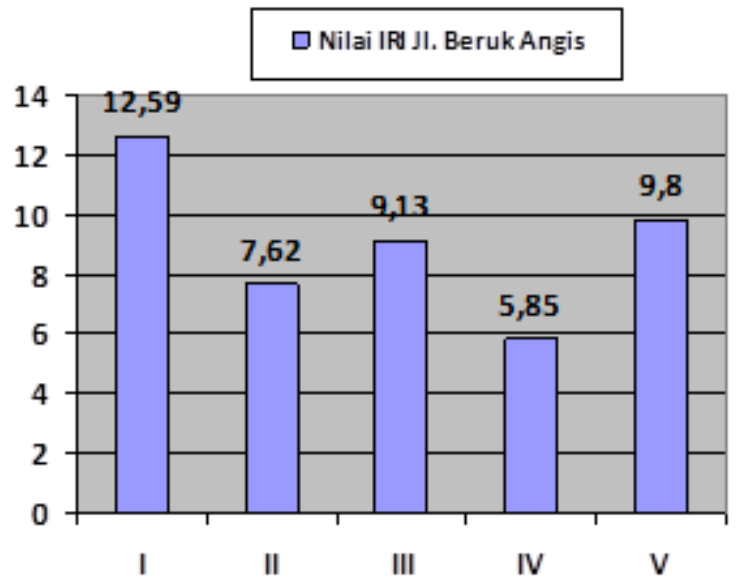

Gambar 7. Diagram nilai IRI pada jalan Beruk Angis

Sumber: Hasil analisis (2021)

Berdasarkan hasil tabel 2 nilai IRI diatas bahwa jalan Beruk Angis diambil 5 segmen jalan. Dengan rata-rata nilai IRI pada jalan Beruk Angis adalah $9 \mathrm{~m} / \mathrm{km}$. Pada gambar 7 nilai IRI tertinggi pada segmen I sebesar $12,59 \mathrm{~m} / \mathrm{km}$. Sedangkan nilai IRI terendah pada segmen IV sebesar 5,85 $\mathrm{m} / \mathrm{km}$. 


\section{Jalan Yos Sudarso}

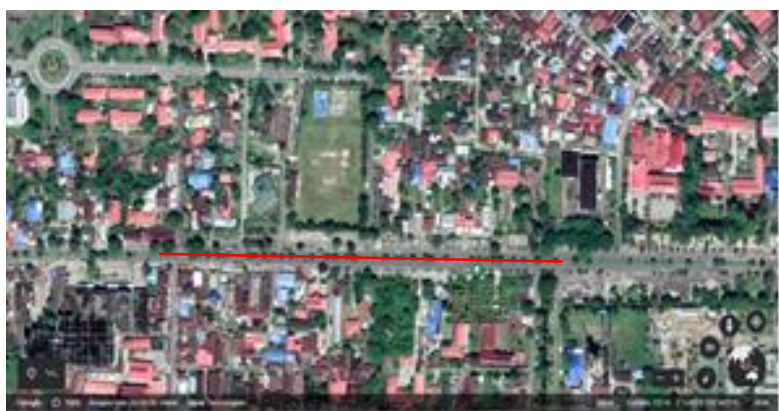

Gambar 8. Lokasi Jl. Yos Sudarso Sumber : Google earth, 2021

Kondisi jalan Yos Sudarso di Kota Palangka Raya seperti pada gambar dibawah ini yaitu:

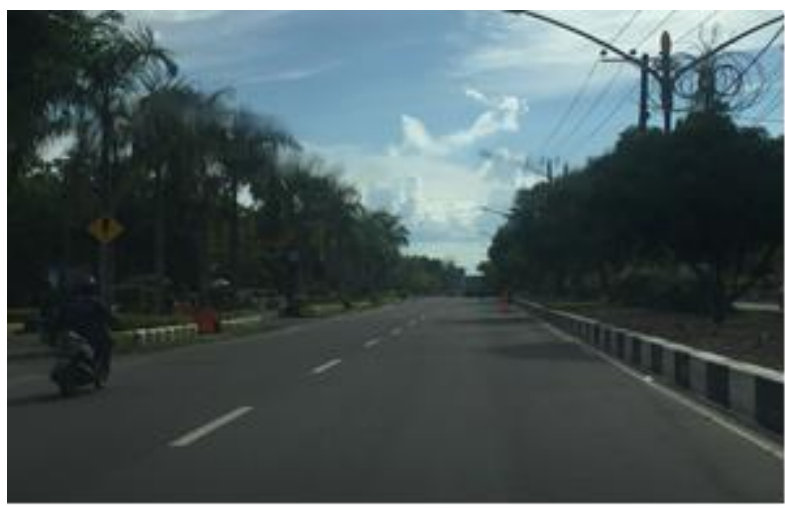

Gambar 9. Segmen I Jl. Yos Sudarso Sumber: Hasil survei 2021

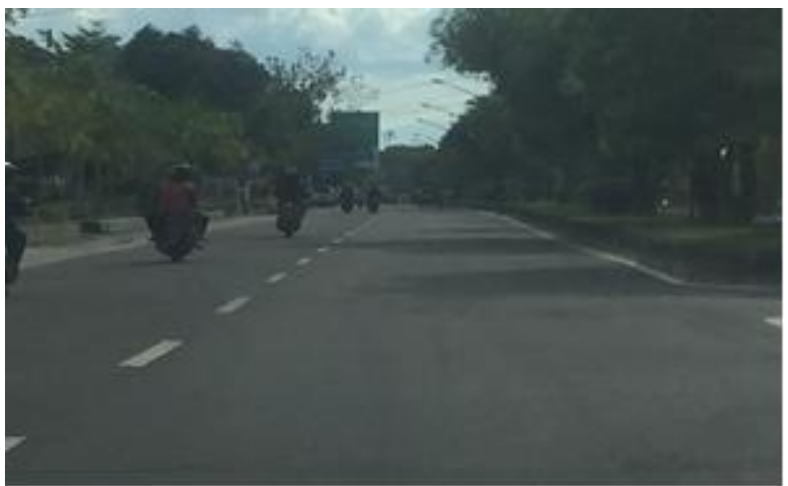

Gambar 10. Segmen II Jl. Yos Sudarso Sumber: Hasil survei 2021

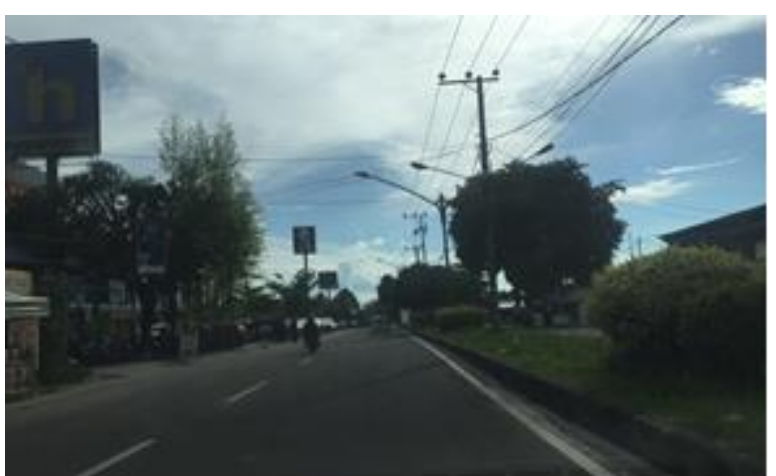

Gambar 11. Segmen III Jl. Yos Sudarso Sumber: Hasil survei 2021

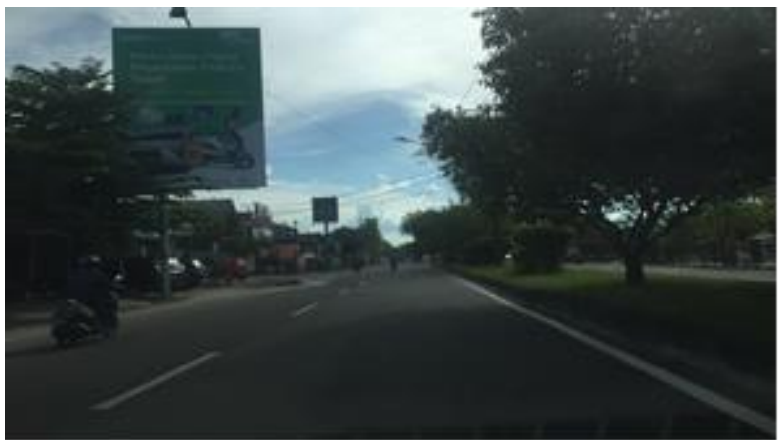

Gambar 12. Segmen IV Jl. Yos Sudarso Sumber: Hasil survei 2021

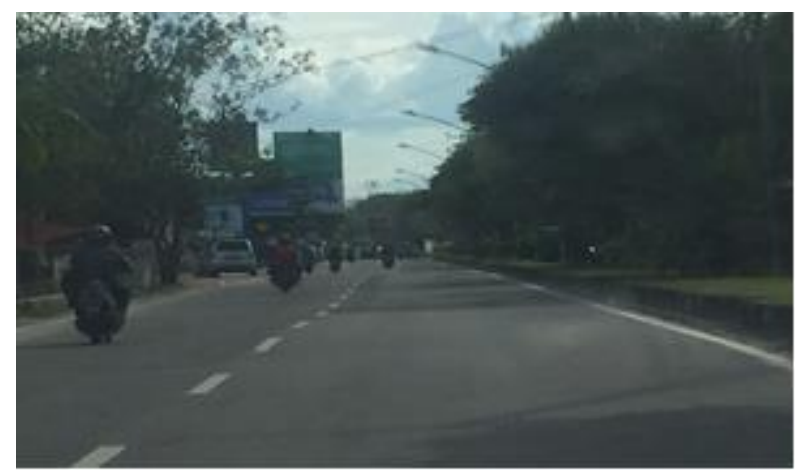

Gambar 13. Segmen V Jl. Yos Sudarso Sumber: Hasil survei 2021

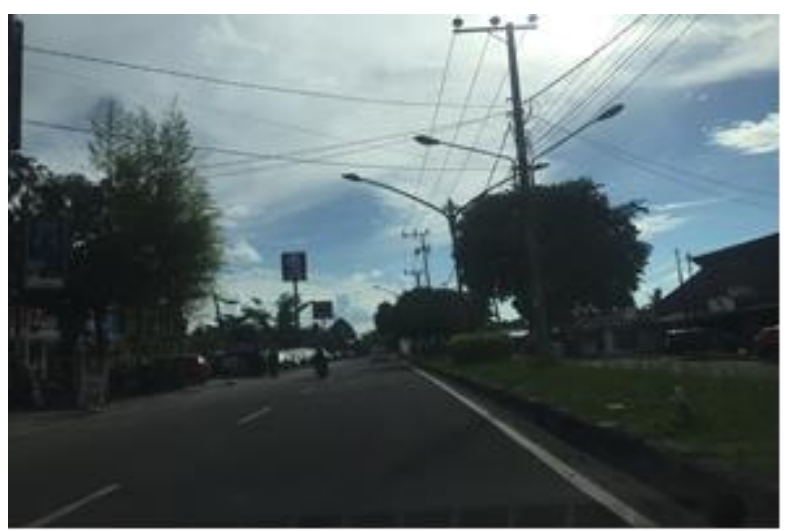

Gambar 14. Segmen VI Jl. Yos Sudarso Sumber: Hasil survei 2021 
Hasil nilai IRI pada jalan Yos Sudarso secara rinci terdapat pada tabel 3 dan Gambar 15 dibawah ini:

Tabel 3. Nilai IRI jalan Yos Sudarso

\begin{tabular}{ccc}
\hline Segmen & Panjang $(\mathbf{m})$ & $\begin{array}{c}\text { Nilai IRI } \\
(\mathbf{m} / \mathbf{k m})\end{array}$ \\
\hline I & 100 & 4,97 \\
II & 100 & 4,83 \\
III & 100 & 5,1 \\
IV & 100 & 4,78 \\
V & 100 & 5,7 \\
VI & 100 & 4,99 \\
\hline
\end{tabular}

Sumber : Hasil Analisis, 2021

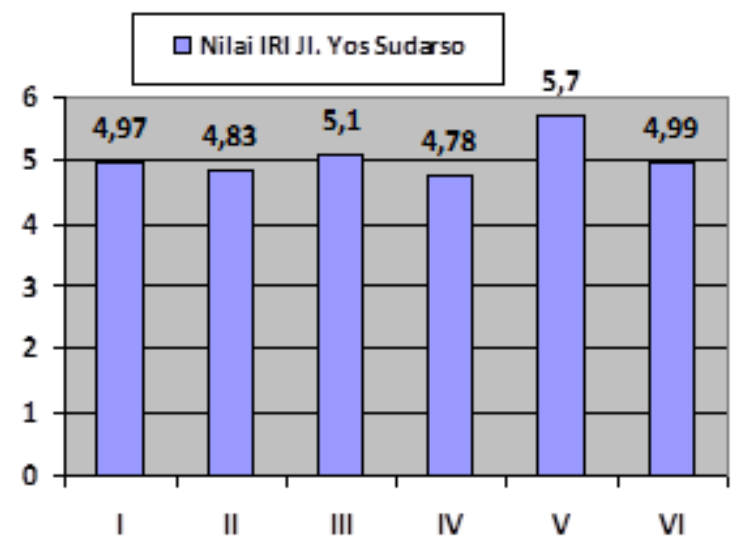

Gambar 15. Diagram nilai IRI pada jalan Yos Sudarso

Sumber: Hasil analisis (2021)

Berdasarkan hasil tabel 3 nilai IRI diatas bahwa jalan Yos Sudarso diambil 6 segmen jalan. Dengan rata-rata nilai IRI pada jalan Yos Sudarso adalah 5,06 $\mathrm{m} / \mathrm{km}$. Berikut dilampirkan diagram nilai IRI pada jalan Yos Sudarso. Pada diagram gambar 15 nilai IRI tertinggi pada segmen $\mathrm{V}$ sebesar $5,7 \mathrm{~m} / \mathrm{km}$. Sedangkan nilai IRI terendah pada segmen IV sebesar $4,78 \mathrm{~m} / \mathrm{km}$.

\section{Jalan Tjilik Riwut}

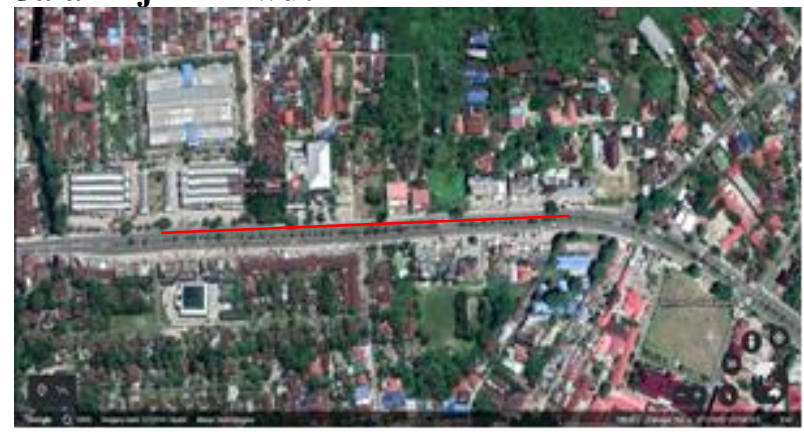

Gambar 16. Lokasi Jl. Tjilik Riwut Sumber : Google earth, 2021
Kondisi jalan Yos Sudarso di Kota Palangka Raya seperti pada gambar dibawah ini yaitu:

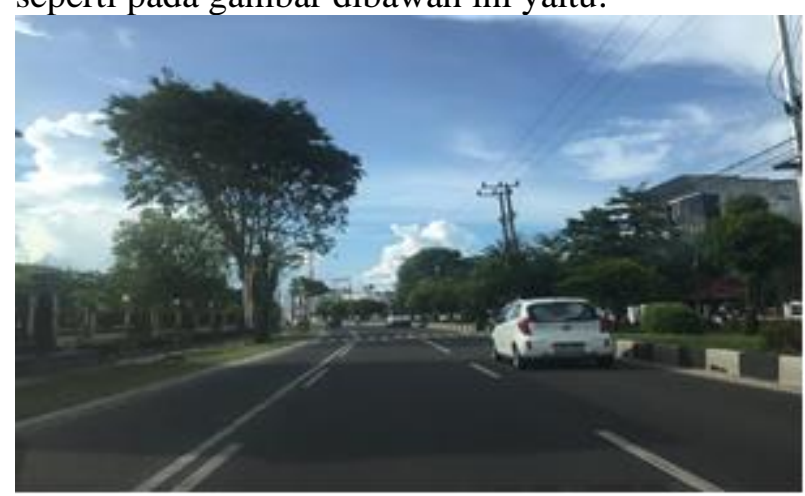

Gambar 17. Segmen I Jl. Tjilik Riwut Sumber: Hasil survei 2021

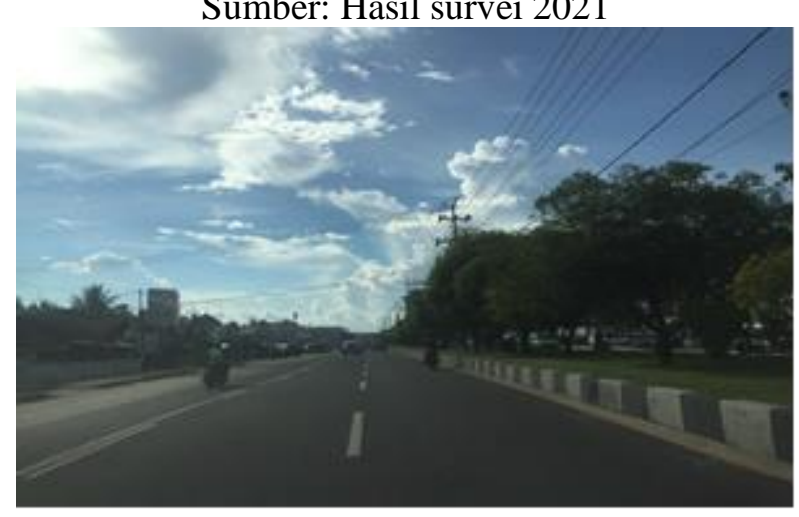

Gambar 18. Segmen II Jl. Tjilik Riwut Sumber: Hasil survei 2021

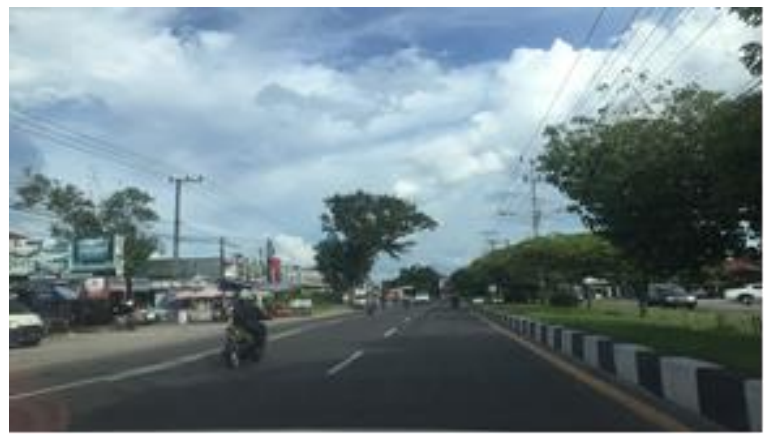

Gambar 19. Segmen III Jl. Tjilik Riwut Sumber: Hasil survei 2021

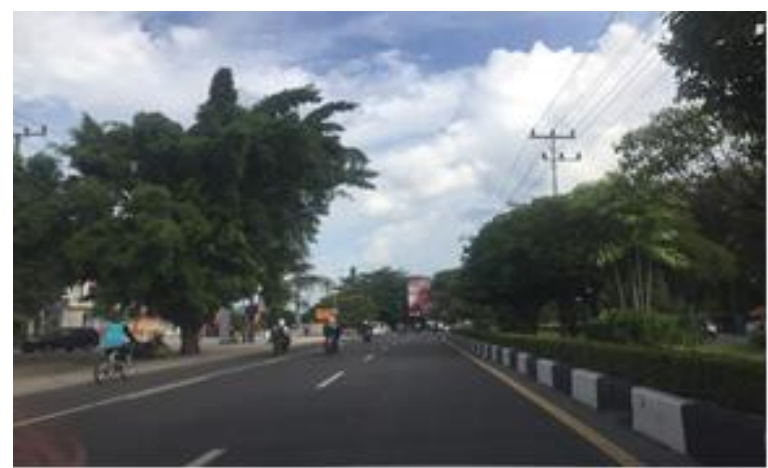

Gambar 20. Segmen IV Jl. Tjilik Riwut Sumber: Hasil survei 2021 


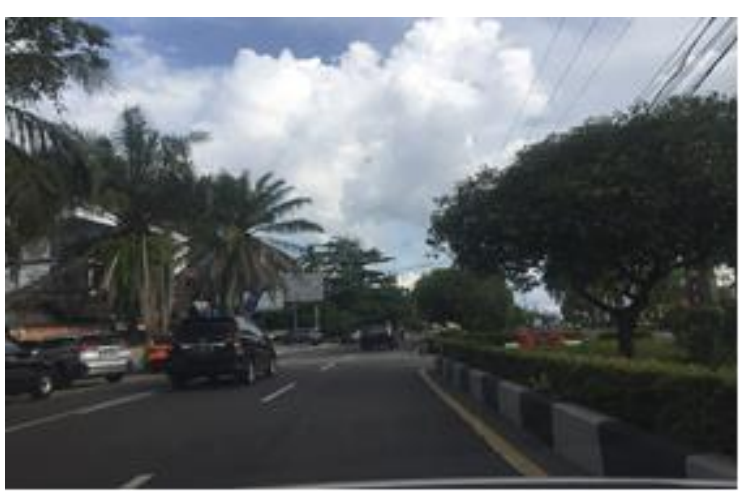

Gambar 21. Segmen V Jl. Tjilik Riwut Sumber: Hasil survei 2021

Hasil nilai IRI pada jalan Tjilik Riwut secara rinci terdapat pada tabel $\mathbf{4}$ dan gambar $\mathbf{2 1}$ dibawah ini:

Tabel 4. Nilai IRI jalan Tjilik Riwut

\begin{tabular}{ccc}
\hline Segmen & Panjang $(\mathbf{m})$ & $\begin{array}{c}\text { Nilai IRI } \\
(\mathbf{m} / \mathbf{k m})\end{array}$ \\
\hline I & 100 & 4,46 \\
II & 100 & 4,19 \\
III & 100 & 5,03 \\
IV & 100 & 4,8 \\
V & 100 & 4,17 \\
\hline
\end{tabular}

Sumber : Hasil Analisis, 2021

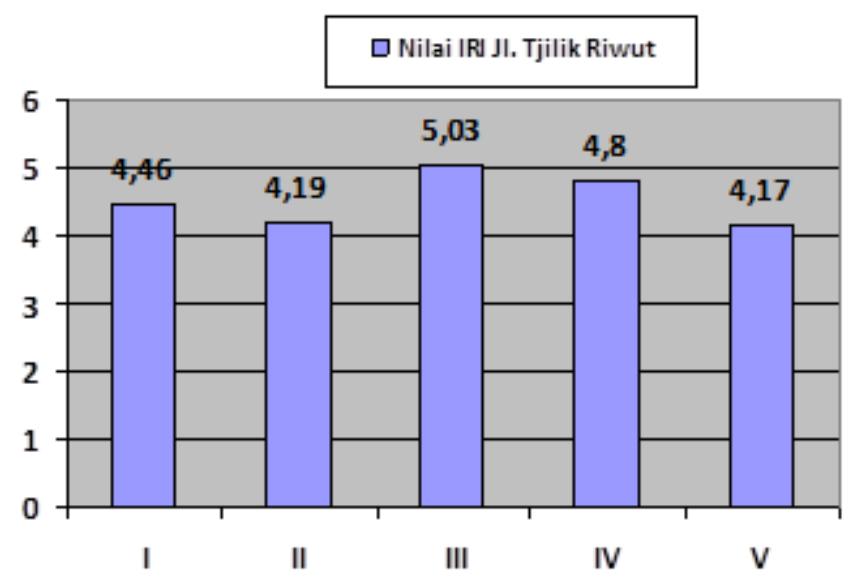

Gambar 22. Diagram nilai IRI pada jalan Tjilik Riwut

Sumber: Hasil analisis (2021)

Berdasarkan hasil tabel 4 nilai IRI diatas bahwa jalan Tjilik Riwut diambil 5 segmen jalan. Dengan rata-rata nilai IRI pada jalan Tjilik Riwut adalah $4,53 \mathrm{~m} / \mathrm{km}$. Berikut dilampirkan diagram nilai IRI pada jalan Tjilik Riwut. Pada diagram Gambar 21 nilai IRI tertinggi pada segmen III sebesar $5,03 \mathrm{~m} / \mathrm{km}$. Sedangkan nilai IRI terendah pada segmen II sebesar $4,19 \mathrm{~m} / \mathrm{km}$.

\section{PENUTUP}

\section{Kesimpulan}

Berdasarkan hasil analisis yang telah didapatkan, maka dapat disimpulkan sebagai berikut:

1. Dari pengujian ketidakrataan jalan yang telah diperoleh aplikasi RoadLab Pro berdasarkan klasifikasi jalan IRI menurut dirjen bina marga yaitu:

a) Jalan Beruk Angis dengan kondisi rusak ringan berdasarkan rata-rata nilai IRI sebesar $9 \mathrm{~m} / \mathrm{km}$. Dan pada segmen I nilai IRI $12,59 \mathrm{~m} / \mathrm{km}$ yang artinya kondisi jalan rusak berat.

b) Jalan Yos Sudarso dengan kondisi sedang berdasarkan rata-rata IRI sebesar 5,06 m/km.

c) Jalan Tjilik Riwut dengan kondisi sedang berdasarkan rata-rata IRI sebesar $4,53 \mathrm{~m} / \mathrm{km}$.

2. Penanganan yang tepat pada ruas jalan Beruk Angis berdasarkan Penanganan Bina Marga yaitu perlu dipertimbangkan untuk peningkatan jalan dan pada segmen I nilai IRI > 12 perlu adanya rekonstruksi.

Untuk ruas jalan Yos Sudarso dan Tjilik Riwut berdasarkan nilai IRI termasuk dalam kategori kondisi kerusakan sedang. Penanganan yang tepat menurut Bina Marga adalah dengan pemeliharaan secara berkala.

\section{Saran}

Berdasarkan penelitian yang dilakukan, maka saran

yang dapat peneliti sampaikan yaitu perlu dilakukannya studi lebih lanjut dengan menggunakan alat dan metode survei yang lain untuk memperoleh hasil yang optimum dan detail dalam merekomendasikan ketidakrataan jalan.

Bagi instansi terkait agar segera memberikan penanganan perkerasan jalan pada kondisi jalan dengan kategori rusak ringan hingga rusak berat.

\section{DAFTAR PUSTAKA}

Direktorat Jendral Bina Marga, (2021). Pedoman Survei Pengumpulan Data Kondisi Jaringan Jalan, Departemen Pekerjaan 
Umum, Jakarta.

Dirjen Binamarga, (1995). Pedoman Teknis

Perencanaan Teknis dan Perencanaan

Program Jalan. Departemen Pekerjaan

Umum, Jakarta

Dirjen Binamarga, (2005). Teknik Pengelolaan

Jalan. Badan Penelitian dan

Pengembangan Pusat Penelitian

Pengembangan Prasarana Transportasi.

Departemen Pekerjaan Umum, Jakarta

Octavia, Syarifah Nur, (2020). Analisis Penerapan

Metode IRI menggunakan Aplikasi

RoadLab Pro dan SDI sebagai Dasar

Penentuan Kondisi Fungsional Jalan (studi

Kasus Ruas Jalan

Pakah-Pucangan-Gesikharjo Sta 1+872 s/d

sta 2+372,Kecamatan Palang), Kabupaten Tuban). Masters Thesis, Untag 1945. Surabaya.

Pratama, Willy, (2020). Analisis tingkat kerataan jalan di Kota Palangka Raya, Universitas Palangka Raya, Palangka Raya 